\title{
TRATAMIENTO DE LOS CONTENIDOS LINGÜÍSTICOS Y GRAMATICALES EN LOS LIBROS DE TEXTO DE LA SERIE: HACIA EL SIGLO XXI
}

Lillyam Rojas Blanco

Resumen: Se centra en los libros de secundaria de la Serie: Hacia el siglo XXI, publicados por la Universidad de Costa Rica y el Ministerio de Educación Pública. Se analizan la presentación y desarrollo de los temas lingüisticos y gramaticales -español de Costa Rica, normas lingüisticas, ortografía, léxico, morfología, sintaxis-, la motivación del alumno y la alumna, la elaboración y presentación de las diversas prácticas y ejercicios. Se destaca que estos textos constituyen un aporte valioso y actualizado para la educación costarricense.
La asignatura Español está organizada a partir de cuatro procesos comunicativos primordiales: la lectura, la escucha, la expresión oral y la expresión escrita; son, pues, actos de producción textual que involucran acción, participación inteligente, complejo procesamiento cognoscitivo y elaboración de sentido. Por tanto, es imprescindible considerar los procesos de recepción como activos. Además, estos últimos abarcan más allá de lo puramente lingüístico, dado que integran conductas relacionadas con el Componente Motivacional -las motivaciones con que se asumen estos actos-, y con el Componente Conceptual (esto es, conocimientos, ideas e información que se expresan y se reciben).

Habida cuenta de lo anterior, es fundamental, en el sistema escolar, propiciar el desarrollo de actitudes favorables hacia el empleo adecuado de la lengua; el desarrollo de procesos cognoscitivos, los cuales permitan establecer relaciones con otros textos, integrar las experiencias y conocimientos previos, analizar, comentar, aplicar, etc. (Marro, 1987). Simultáneamente, estos motivos y conocimientos se organizan y traducen al código de la lengua. En dicha traducción, desempeña un papel importante el tercer componente, el Lingüístico, que involucra aspectos tales como los subcomponentes pragmático, discursivo, notacional, etc. (Rojas, 1991).

Los contenidos propiamente dichos se organizan en varias áreas, tales como literatura, 
expresión escrita, expresión oral, escucha, ortografía, morfología, sintaxis, lingüística. En los párrafos siguientes, concentraremos la atención en la interacción entre los elementos ya mencionados y el desarrollo de los contenidos lingüísticos y gramaticales en los libros de texto del III Ciclo, de la Serie Hacia el Siglo XXI. Todos los ejemplos que citaremos corresponden a los libros de texto de los niveles de octavo y noveno; entre paréntesis indicaremos el nivel y el número de página respectivos.

\section{El tratamiento de los contenidos lingüísticos}

\section{Comunicación eficaz y adecuada}

En la vida en comunidad, entablar relaciones interpersonales y comunicarse resultan comportamientos no sólo naturales sino también necesarios para los seres humanos. Pese a que la persona, para comunicarse, puede recurrir -y de hecho lo hace- a medios averbales (gestos, palmadas, ademanes, posición corporal, etc.), no cabe duda de que la lengua constituye un recurso fundamental para la comunicación (Alcalá, 1981). Asimismo, lingüísticamente hablando, ninguna forma de expresión es mejor que otra; no obstante, deben reconocerse, en la comunicación lingüística, las distintas normas coexistentes, cuya naturaleza es estilística, geográfica, estadística o social (Alcalá, 1981: 40 y ss).

Por tal motivo, se busca que los estudiantes entren en contacto con la lengua viva; para ello, aparte de los textos escritos, se integran textos orales. Asimismo, se hace hincapié en que en el sistema educativo deben estudiarse todas las normas, dado que el español (en concreto el de Costa Rica, centro de interés), es un haz de variedades lingüísti- cas, una de las cuales, la prescriptiva, por criterios de estética lingüística, purismo, autoridad, etc., se constituye como código en situaciones de comunicación sobre temas formales, con participantes formales y canales también formales. A través de uno de los personajes masculinos se reconoce la importancia de la norma culta, según se aprecia en la Figura $\mathrm{N}^{\circ} 1$ (9º́ng. 7).

Aprender la norma culta permite un mejor acceso a los bienes y servicios, a la educación, una mejor interacción social y lingüística.

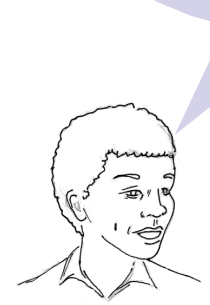

Fig. $N^{\circ} 1$

Es fundamental indicar que, en todos los temas y subtemas, se presentan figuras de diversos personajes adolescentes - de uno y de otro sexo, e, incluso, se incorporan personajes con algún tipo de limitación física-, a través de cuyas intervenciones se canalizan posibles dudas de los estudiantes y se refuerzan y se comentan diversos aspectos de los temas en tratamiento; el objetivo es que se identifiquen con ellos y que se establezca una actitud dialógica. De tal modo, se facilita que los alumnos y alumnas expresen sus inquietudes y críticas, y se refuerza la relación profesor-alumno en el aula. Lo anterior se ejemplifica en la Figura $N^{\circ} 2\left(9^{\circ}\right.$, pág. 8): 
Y, entonces, ¿cuál de las normas tenemos que aprender en el sistema educativo?

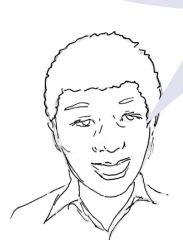

Todas. El español de Costa Rica es un haz de variedades lingüísticas cuyos elementos tienen similar distribución social, una de las cuales, por razones mencionadas, se constituye como código en situaciones de comunicación sobre temas formales, con participantes formales y canales también formales.

Fig. $N^{\circ} 2$

Por consiguiente, el tema se desarrolla mediante un diálogo progresivo entre el narrador y los personajes adolescentes, quienes comentan, opinan y plantean diversas inquietudes. Por un lado, se subraya la idea de que hay que reconocer la diversidad de normas en el español; información que se presenta en boca de un personaje adolescente femenino, según puede observarse en la Figura $\mathrm{N}^{\circ}$ 3, del libro de texto de noveno (pág. 7).

Entonces, en este sentido, existen muchas normas: la uruguaya, la ecuatoriana, la cubana, la nicaragüense, la costarricense, etc.

Fig. $\mathrm{N}^{\mathrm{o}} 3$

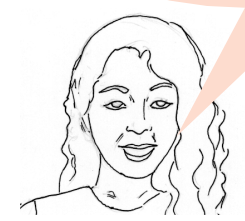

Por otro lado, se insiste, a través de uno de los personajes (véase la Figura $\mathrm{N}^{\circ} 4$; $9^{\circ}$, pág. 9), en que debe sentirse orgullo y lealtad hacia todas las variedades lingüísticas costarricenses, dado que en ellas se refleja nuestra cultura, historia e identidad y porque, además, permiten la distinción de los otros pueblos hablantes del español.

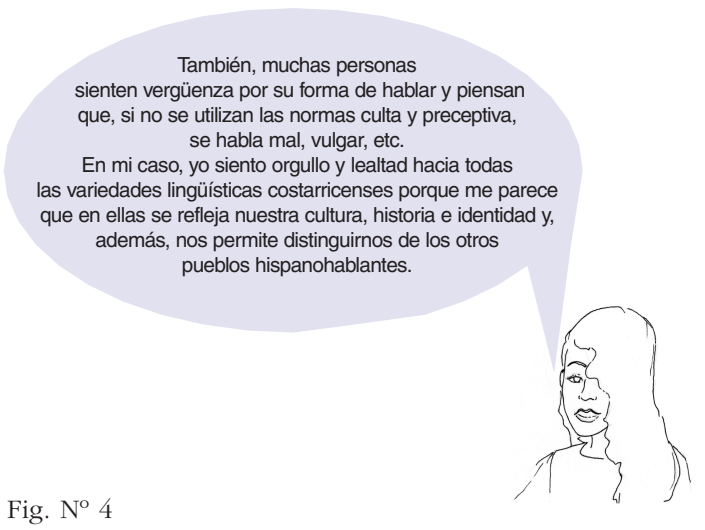

Uno de los aspectos cruciales, en el tratamiento de este contenido, es el hecho de incorporar el criterio de adecuación, aplicado a situaciones lingüísticas reales; se insiste en que el enunciado lingüístico ha de ser adecuado según la situación comunicativa del caso (Alcalá, 1981: 44-45). Dependiendo de la relación entre los interlocutores, de los propósitos de la comunicación y de la situación (formal o informal), se decide qué decir y en qué términos (subcomponente pragmáticodiscursivo). Ello conduce a la concepción de que no existe una sola forma correcta de hablar, sino varias, lo cual no da cabida, de ninguna manera, a la anarquía en la expresión lingüística, dado que se enfatiza el hecho de que la norma culta también ha de estudiarse (recuérdese la Figura $\mathrm{N}^{\circ}$ 1). Así, en boca de uno de los personajes, se incorpora, en forma sucinta, la información ( $9^{\circ}$, pág.8); véase la Figura $\mathrm{N}^{\circ} 5$. Por último, lo anterior remite a la premisa constructivista de que no hay una única realidad, sino construcciones que constituyen nuestra visión de mundo. 
Fig. $\mathrm{N}^{\circ} 5$

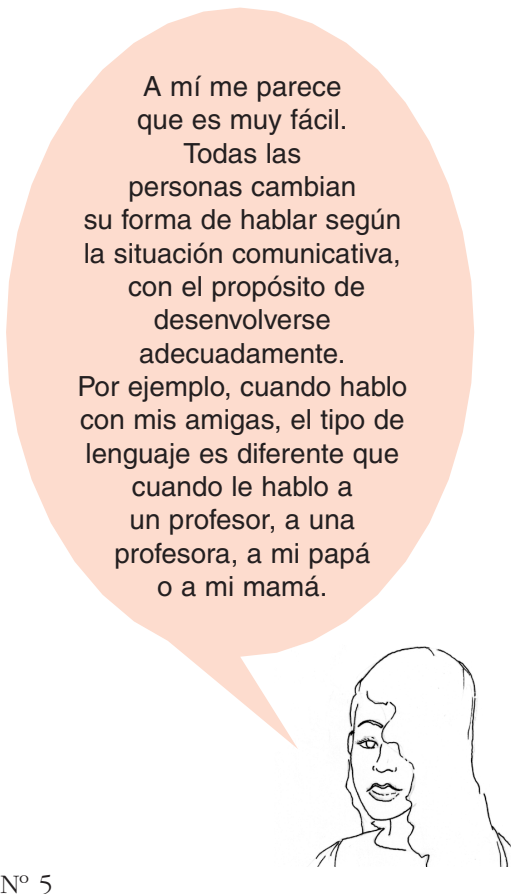

En fin, se logra el distanciamiento de un enfoque meramente normativo, el cual ha suscitado que se considere que el estudio de la lengua se centra en reglas de uso, en el criterio de "corrección", según el cual comúnmente se maneja la idea de que tal palabra "no se dice", "no debe decirse" e, incluso, "no existe" porque no se registra en el diccionario, entendido éste en general como el Diccionario de la lengua española, de la Real Academia de la Lengua.

El capítulo destinado a este tema lleva por título: "QQuiénes se comunican eficazy adecuadamente?", lo cual es síntoma de que, desde el inicio, se pretende un distanciamiento de la postura de lo "correcto". Inmediatamente después, se invita a embarcarse en la aventura del lenguaje y a reflexionar, a partir de lo que ellos ya saben y conocen, a partir de lo que se les ha inculcado prácticamente toda su vida -"lo correcto"- y sus experiencias al respecto, tal como puede observarse a continuación:

"Inicie esta gran aventura. Va a conocer algunos principios teóricos que le permitirán comprender mejor la comunicación eficaz y la ubicación de usted como habitante de un país llamado Costa Rica. ¡Adelante!
Qué experiencias positivas y negativas ha tenido en relación con "comunicarse correctamente"? Discuta con un compañero o compañera lo que usted entiende por "comunicarse correctamente". (9, pág. 6).

Por otra parte, es primordial señalar que se persiguen premisas constructivistas relativas a que el conocimiento es una construcción social, donde el sujeto es constructor del conocimiento y el sujeto, a la vez, se construye conjuntamente con el objeto de conocimiento. En este marco, es de primordial importancia el papel del juego como medio para transmitir, además de los diversos conocimientos, conceptos, valores, en un contexto más "relajado" que el que comúnmente se percibe en el aula de español. Para ello, en los ejercicios y prácticas, se insta a los estudiantes a la participación activa en el uso del lenguaje oral, en la discusión grupal y en la toma de decisiones, en la práctica de diversas actividades lúdicas, con todo lo cual, paralelamente, se promueve la toma de conciencia de deberes y derechos en la interacción comunicativa con los demás; se parte, pues, de ejemplos concretos, de lo que los estudiantes y las estudiantes ya saben como hablantes nativos del español, con el propósito de que, a partir del caso o ejemplo concretos, ellos propongan la regla. Se ofrecen textos literarios, textos orales, textos periodísticos, etc., con el fin de reafirmar su contacto con el registro escrito y con el oral.

No estamos emitiendo juicios de valor respecto de ninguno de los registros, por cuanto ninguno es "mejor", "más correcto" que el otro; únicamente cabe decir que son diferentes y sirven a fines distintos. Ello no obsta para enfatizar la comparación entre ambos registros, puesto que de ahí se parte para reconocer muchos de los problemas presentes en la comunicación escrita, por interferencia del registro oral en la práctica de escritura. Sobre el particular, señalan Rodino y Ross (1985, 35):

"Su tarea principal [de la escuela] debe consistir en concientizar al usuario de la lengua de los procesos lingüisticos y su valor para que, conociéndolos, pueda manejarlos en su práctica cotidiana de hablante. [...] Uno de los problemas lingüísticos más serios que enfrenta con- 
temporáneamente la enseñanza costarricense -a saber, la deficiencia en la expresión escrita- surge de la escasa conciencia y práctica de la diferenciación entre las variedades funcionales (registros) oral y escrita". (El destacado es de los autores).

\section{El español de Costa Rica}

Es importante poner de relieve que, en los libros de texto de la Serie Hacia el Siglo XXI, se aborda el estudio del español de Costa Rica en toda su diversidad. En el texto de octavo año, el énfasis está en las variedades léxicas; en el de noveno año, en las variedades morfológicas y fonéticas.

En el texto de octavo año, el tema se introduce por medio de dos textos, uno es del registro escrito y el otro constituye una transcripción de un texto oral, con sus pausas y elisiones de sonidos. Seguidamente, propone un trabajo de reflexión alrededor de los textos; en esta labor, se le pide al estudiante determinar diferencias entre ambos registros (oral, escrito) $\mathrm{y}$, además, se le presenta una pregunta tendiente a examinar sus actitudes lingüisticas. Otro aporte interesante radica en el hecho de que se destacan las lenguas indígenas costarricenses como tales, no como son popularmente denominadas ("dialectos", desviaciones de una supuesta norma o lengua prestigiosa) y su variante léxica; se enfatiza, pues, la cualidad plurilingüe de nuestro país.

En cuanto al libro de noveno año, el tema inicia con un fragmento del registro oral de un informante puntarenense. Y se lleva al alumno a reflexionar acerca de si todos los costarricenses hablan igual, y a señalar las palabras que más le llamaron la atención y la razón de ello.

Así, entonces, se presentan las dos zonas dialectales diferenciadas: la del Valle Central y la del Noroeste, en las cuales se estudian tanto las características compartidas como las que particularizan a cada zona; con lo anterior, se pretende que los estudiantes tengan acceso a la lengua viva y se reconozcan, también, como hablantes de un dialecto particular; ello puede apreciarse en la Figura $\mathrm{N}^{\circ}$ 6 (9º́, pág. 12).

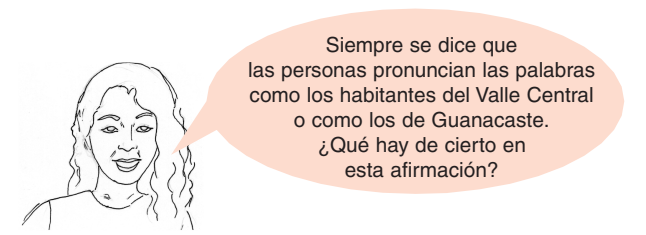

Para contestarle, hay que aclarar que, en Costa Rica, se distinguen actualmente dos grandes zonas dialectales: la del Valle Central y la del Noroeste. Esta última se extiende por toda la provincia de Guanacaste, la parte sureste de la Península de Nicoya, la banda oriental del Golfo de Nicoya hasta la ciudad de Esparza y la parte noroeste de la provincia de Alajuela.

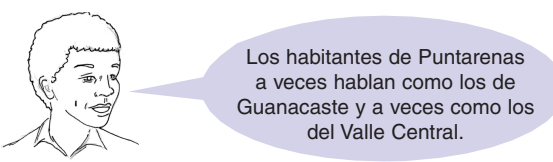

Ciertamente, estas grandes zonas no constituyen bloques homogéneos y diferenciados; por ejemplo, la ciudad de Puntarenas comparte rasgos con ambas zonas dialectales mencionadas.

Fig. $N^{\circ} 6$

A título de ejemplo, cabe mencionar que se revisan las diversas pronunciaciones de /r/ en el español del Valle Central, así como se remarca la pronunciación, en el español del Noroeste, de los grupos [tr] y [dr] $\mathrm{CO}^{-}$ mo dos sonidos claramente distinguibles.

En fin, en los textos, se busca presentar los diversos fenómenos lingüísticos de modo inductivo, de forma amena, tratando de entablar un diálogo con los estudiantes; se evita, asimismo, cualquier referencia a la corrección, al hablar "bien" y a la idea de que una palabra "no existe" o "no se dice". En las prácticas, se los insta a reconocer diferencias y semejanzas entre formas de hablar. Obsérvese la Figura $\mathrm{N}^{\circ} 7$ (9º́, pág. 16).

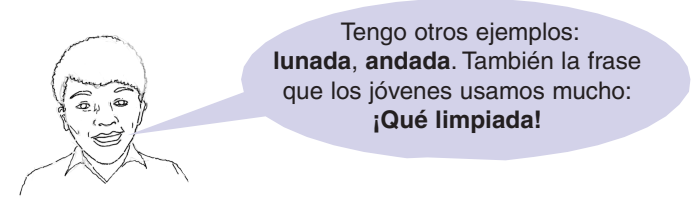

Tiene razón. Esta frase que Gebe citó se emplea mucho en el habla coloquial, no lo olvide.

Fig. No 7

En relación con el Componente Motivacional, se propone un arribo a los actos de lengua como una aventura estimulante, sorprendente y productiva, con actividades y ejercicios que propicien el juego, la reflexión, la criticidad y la creación. Se conciben los textos oral y escrito, entonces, como pretex- 
tos para la creación de otros textos y para la elaboración de nuevos sentidos.

En los ejercicios de la siguiente cita, el énfasis está en la búsqueda y ejemplificación de las características de las zonas dialectales del español de Costa Rica, principalmente en los medios de comunicación y en los del transporte público, en lugares donde se aglomera la gente; asimismo, se centra la atención en la actividad de una obra de teatro para representar dichas diferencias. También, se presentan preguntas que impliquen análisis y razonamiento de las respuestas.

“- ¿Ha escuchado cómo pronuncia una persona de la Zona Noroeste y una del Valle Central el grupo de sonidos "tr"? Comente y determine las diferencias.

-Escuche un radioperiódico o un telenoticiario; primero, preste atención a la pronunciación de la ese, luego a la pronunciación de "tr", de erre y de ere. (...) Escuche un noticiario internacional y determine características fonéticas en común o distintas de las formas de habla de las dos zonas dialectales de Costa Rica.

[...]

-Escuche conversaciones en los autobuses, en los restaurantes de su comunidad y trate de encontrar ejemplos de las características fonéticas recién observadas.

-Prepare una pequeña obra de teatro, en conjunto con tres compañeros o compañeras, y represente las diferencias en las formas de habla de las dos zonas dialectales del país" (9º pág. 15).

"-Cite algunas diferencias que haya notado entre hablas de distintos grupos sociales o de distintas regiones de Costa Rica.

¿En qué código se ha escrito la Constitución Política de Costa Rica? ¿Por qué? Consulte ese documento, título 7, capítulo único, artículo 76.

¿Le parece a usted que la variedad del español empleada por un campesino es una corrupción de la lengua española? Razone su respuesta." (8º́ng. 13).

En la cita siguiente ( $9^{\circ}$, pág. 18), se presenta un extracto de un texto oral, así, con todas las variantes de pronunciación que evidenció el informante; después del texto, viene una serie de preguntas para trabajar, reflexionar y construir a partir de éste:

"Sí, sobre el dueño e monte, pero yo iba a la finca onde el papá e nojotros, el padre Vargas, que tenía finca en el "Muy" y a caballo, veá, pero yo ya jugaba futbol pero él era enemigo de que yo jugara futbol entonces llegándole a las seis de la mañana a este lao del yurro e San Car- los, no había ningún problema. Pero si yo llegaba tarde el peligro era ese, pero entonces me decía la gente: -No se vaya de madrugada porque allí asusta el dueño e monte-".

También, aquí se establece una interrelación necesaria entre las diversas normas existentes y el criterio de variación dialectal, por cuanto ha de inculcarse en los jóvenes, por una parte, la necesidad de orgullo y lealtad por la variante propia y, por otro, una actitud de verdadero respeto y tolerancia por otras variantes dialectales o por otras lenguas, sean aquéllas y éstas consideradas más prestigiosas o no.

\section{El tratamiento de los contenidos gramaticales}

\section{Ortografia}

El compromiso de enseñar ortografía debe ubicarse dentro de un marco mayor: empleo adecuado del registro escrito. Para ello, la ortografía debe atenderse sistemática, progresiva y gradualmente; también, de manera informal y ocasional; los temas de ortografía, en consecuencia, se distribuyen a lo largo del libro.

Se parte de lo que el alumno sabe y usa, para lograr su madurez lingüística, en un proceso sistemático e inductivo, integrado a situaciones comunicativas reales.

Como parte del tratamiento del tema, se privilegian las prácticas que propician la interiorización de los patrones visuales de la escritura adecuada, procurando el desarrollo de la memoria visual. Resulta fundamental la práctica lúdica para incentivar el mejoramiento de la ortografía; a través del juego, enriquecen su vocabulario y fijan el conocimiento ortográfico.

A título de ejemplo, podemos referirnos a la introducción al capítulo $\mathrm{N}^{\circ} 6$, según puede apreciarse en la Figura $N^{\circ} 8\left(9^{\circ}\right.$, pág. 56), en que, en una caricatura, se establece un juego de palabras entre "pollo" (ave de corral) y "poyo" (asiento de un parque). Posterior a la imagen, se le plantea al estudiante 
la interrogante "¿por qué el personaje se expresa de ese modo?", con el fin de que éste procure determinar el problema ortográfico.

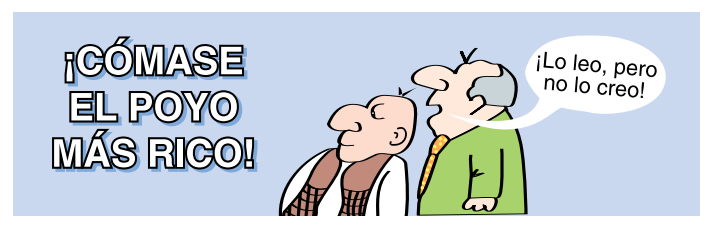

Fig. $N^{0} 8$

Otro ejemplo puede apreciarse en la presentación del tema de reglas ortográficas sobre la "b" y la "v" donde, primeramente, se invita al estudiante a refrescar la memoria en relación con las reglas ya estudiadas; seguidamente, se presenta una estrofa alusiva a la "b" ( $9^{\circ}$, pág. 63), tal como puede observarse a continuación:

"La be es una letra bella, aparece en biología, benefactor y todas las formas de percibir; por eso, a esta estrella, todos salen a recibir."

También, en la Figura № 9 (9º pág. 63), puede apreciarse la presentación de ejemplos de infinitivos y conjugación verbal en varios tiempos en relación con el uso de "be" los infinitivos de los verbos terminados en "bir" y sus conjugaciones. A partir de los ejemplos, se introduce la regla y luego, a través de uno de los personajes, se presenta la regla correspondiente.
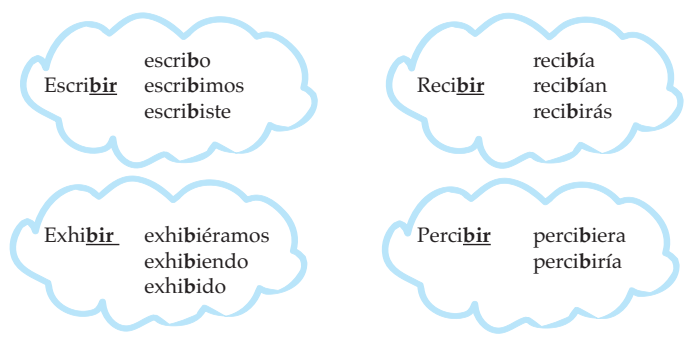

Fig. $\mathrm{N}^{\circ} 9$

Específicamente, se promueven actividades que obedezcan a finalidades específicas tales como:

1. Lograr fijar la atención en una característica determinada de la palabra, utilizar color y otros recursos para señalar los elementos que necesitan atención.

2. Trabajar con la estructura de la palabra, para que cada letra tenga su propia importancia.

3. Cumplir con el propósito de no escribir palabras sin conocer su significado: se busca la elaboración de diccionarios pictóricos, la solución de crucigramas, etc.

4. Propiciar la autocorrección ortográfica.

5. Ejercitar la memoria visual.

En el tema de la "j", por ejemplo, se observa un personaje en forma de jota, el cual habla y presenta la regla correspondiente, según puede verse en la Figura $\mathrm{N}^{\circ}$ 10 (9, pág. 86).

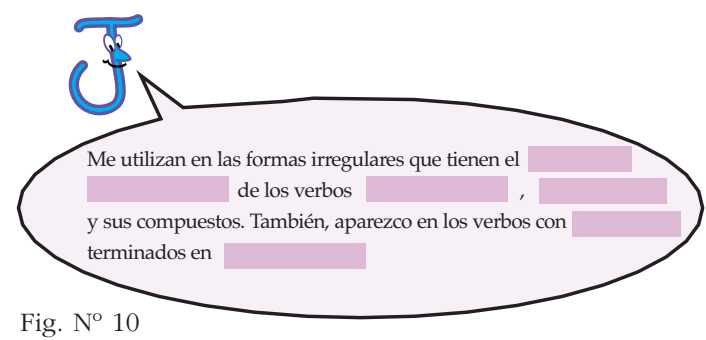

En el tema de la "h", se les pide a los alumnos y alumnas que formen grupos y preparen los materiales para el juego "El dado y las cajas", el cual consiste en extraer -y contestar- preguntas de una de tres cajas numeradas de uno a tres, respectivamente.

A lo largo de todos los temas, no sólo el de ortografía, se procura incorporar el elemento lúdico. En los últimos años, se le han otorgado al papel del juego en la educación nuevos fundamentos teóricos, por cuanto se considera que "...el juego es una función importante del desarrollo, del aprendizaje y del bienestar del niño en todas las áreas vitales y es justamente imprescindible" (Walter, 1993: 177).

A través del juego, el ser humano, en sus primeros años de vida, conoce el mundo circundante, incluyendo personas, objetos, 
funcionamiento de éstos y forma de manejarse de las personas cercanas; por todo ello, no podemos excluir el juego del ámbito de la educación formal, puesto que el aprendizaje a través de situaciones lúdicas es mucho más enriquecedor. Por otro lado, son múltiples las posibilidades educativas y de aprendizaje que brinda el juego libre y espontáneo. Trautmann (1995: 65)) comenta:

“... considero interesante el desafío de fomentar, favorecer y apoyar el juego activo, participativo, comunicativo y relacional entre los niños, frente a una cultura de avanzada que estimula cada vez más la pasividad aún corporal, receptividad consumista frente a una imagen/pantalla".

\section{Morfología y sintaxis}

La morfología, la sintaxis, las relaciones de las palabras en la oración, sus ordenamientos, conexiones, formantes, etcétera, constituyen un aspecto de la lengua que debe considerarse en la comprensión y producción del texto, tanto en la expresión oral como en la escritura.

El punto de partida (lo que el estudiante sabe y utiliza) y la ejercitación, buscan lograr su madurez lingüística, id est, que adquiera la habilidad de producir enunciados de mayor complejidad estructural, partiendo de lo ya conocido -los conceptos importantes se repasan en recuadros-, todo se reúne en un proceso sistemático e inductivo, orientado también a situaciones comunicativas reales. Se evita atender los procesos como análisis en sí mismos y se busca el contacto con la lengua y al servicio de la producción de textos claros, expresivos, coherentes, tanto orales como escritos, en la vida cotidiana y escolar.

El sujeto, el verbo, los complementos verbales, etc., se organizan en estructuras arbóreas (con forma de árbol invertido), donde se integran las nociones de sujeto y de predicado, junto con la segmentación morfológica general. Este sistema de trazado se utiliza en semántica. Gradualmente, se incluyen oraciones de mayor complejidad estructural.

Esta metodología persigue que los adolescentes integren la morfología y la sin- taxis. También, dada la configuración de las estructuras arbóreas, se facilita la interiorización del análisis, la memoria visual.

Asimismo, permite integrar los conceptos de frase nominal y frase verbal dentro del análisis sintáctico general. Se puede apreciar claramente que los sujetos están constituidos por frases nominales.

En cuanto a la oración copulativa, en el libro de octavo año se parte de preguntas para reflexionar sobre lo aprendido el año anterior. Se enfatiza el modo de reconocer el sujeto, el hecho de que las cualidades que se atribuyen al sujeto se expresan por medio de un adjetivo en el complemento predicativo. Se presenta de manera esquemática la estructura de la oración copulativa y se ejemplifica su estructura arbórea, según puede apreciarse en la Figura $N^{\circ} 11$ ( $8^{\circ}$, pág. 87).

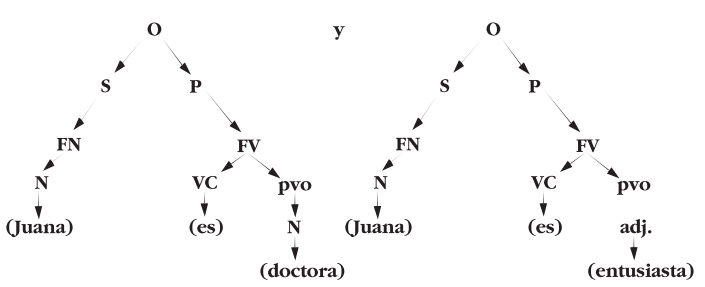

Fig. $\mathrm{N}^{\mathrm{o}} 11$

En el libro de noveno, se repasa el complemento predicativo (CP); se parte de un grupo de versos para pedir al alumno reflexionar sobre el tema. A través de uno de los personajes se refuerza la idea del valor de cópula de ser y estar; luego, se destaca el porqué de los términos predicado nominal y complemento predicativo.

Por otra parte, para comprender mejor la oración predicativa, se ofrece un ejemplo de una oración desarrollada con el mismo sujeto y un predicado verbal que varía en su constitución desde incluir solo al verbo hasta incorporar CD, CI y CC (8 , pág. 182).

En cuanto a los complementos verbales, desde el título ( $9^{\circ}$, pág. 110) que aborda el tema se enuncia su papel: "EL VERBO Y SUS AYUDANTES: LOS COMPLEMENTOS VERBALES", y, a continuación, se le recuerda al estudiante el valor del verbo como núcleo del predicado. 
“¿Recuerda cúal es el núcleo del predicado? ¡Claro! Es el verbo. Por esta razón, se denomina predicado verbal."

Se presentan el complemento directo, el complemento indirecto y el complemento circunstancial numerados, respectivamente, como C1, C2 y C3; si aparece más de un complemento circunstancial, se numerará C4, etc. La configuración permite apreciar la presencia de frases preposicionales en los diversos complementos y su ubicación lógica en la oración.

Con respecto al complemento directo (CD), en la Figura $\mathrm{N}^{\circ} 12$ (9 , pág. 111), puede apreciarse su constitución; a veces es sólo una frase nominal (como en "unos zapatos"); otras, una frase preposicional, constituida por preposición más frase nominal ("a Pascual").

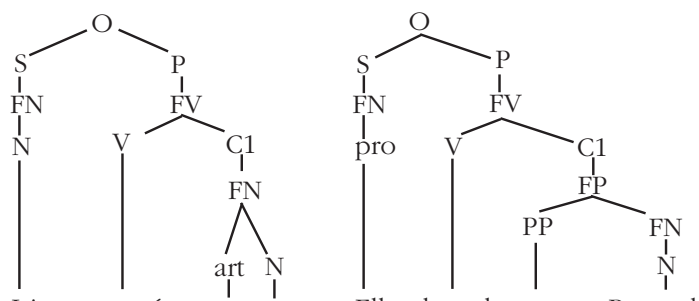

Iris compró unos zapatos Ellos buscaban a Pascual Fig. $\mathrm{N}^{\mathrm{o}} 12$

Para el reconocimiento del complemento directo, en el libro de octavo año se ofrecen varios ejemplos de oraciones con diversos CD y se cambian éstos por los respectivos pronombres átonos, en el procedimiento denominado pronominalización ( $8^{\circ}$, pág. 200). En el libro de $9^{\circ}$, se echa mano de la intervención de uno de los personajes, para presentar al estudiante esta prueba de sustitución del CD; véase la Figura $N^{\circ}$ 13 (9, pág. 111).

- Note que es posible efectuar algunos cambios es estos predicados: Iris los compró; Lo buscaban. ¿Qué sucedió?

\section{Los complementos directos} unos zapatos negros y a Pascual fueron sustituidos por los y lo, los cuales son pronombres de complemento directo; por tanto, todo modificador que pueda ser sustituido por alguno de ellos es también un C1.

Fig. $N^{0} 13$
En relación con el complemento indirecto $(\mathrm{CI})$, mediante un personaje masculino se muestra cómo reconocerlo, según puede observarse en la Figura $N^{\circ} 14$ ( $9^{\circ}$, pág. 112).

Yo observo que "para la hija de

Hugo" es el complemento indirecto y especifica el beneficiario de la compra y responde a la siguiente pregunta: ¿A quién o para quién compró Iris unos zapatos?

Fig. $\mathrm{N}^{\mathrm{o}} 14$

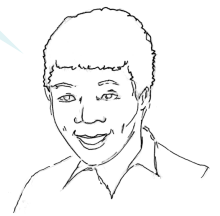

Se enfatiza el valor de frase preposicional del CI y su posible sustitución por los pronombres átonos le, les, tal como puede observarse a continuación ( $9^{\circ}$, pág. 113):

"El C2 puede ser sustituido por pronombres como le y les, los cuales funcionan siempre como complementos indirectos.

En estas dos oraciones: "Micaela dio una flor a su novio", "Ana compró un carro a sus papás", los C2 (complementos indirectos) pueden ser sustituidos y quedan como resultado las siguientes formas: "Micaela le dio una flor", "Ana les compró un carro". Note que en un caso le está en singular debido a que el C2 "a su novio" está también en singular; en el otro caso, les aparece en plural..."

En cuanto a los complementos circunstanciales (CC), se distingue que pueden estar constituidos tanto por frases adverbiales como por frases preposicionales.

En este punto, es importante destacar que el tema inicia con la oración "Iris compró unos zapatos", en la cual se destaca el CD; luego, conforme avanza el tema, se obtiene mayor complejidad estructural pues van añadiéndose el CI, el CC de lugar y el CC de tiempo; hasta quedar la estructura arbórea como en la Figura $\mathrm{N}^{\circ} 15\left(9^{\circ}\right.$, pág. 114).

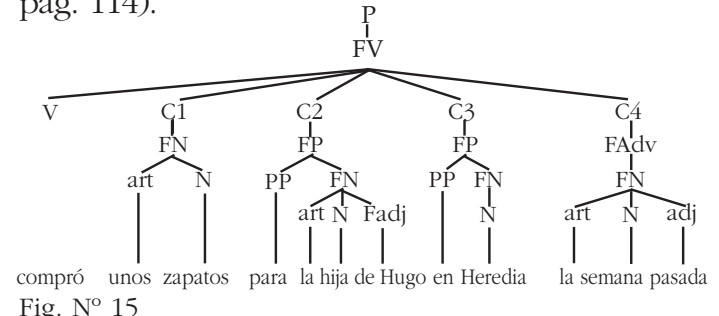


Una vez estudiados los complementos verbales, se centra la atención en la oración transitiva. La distinción entre oración transitiva e intransitiva queda clara al apreciar visualmente la ausencia del C1 (CD) en la segunda. Por ejemplo, en el libro de noveno (pág. 142), desde el título del capítulo destinado a la oración transitiva, se refuerza la idea del CD: "La oración transitiva: atrape al complemento directo".

Se parte de nuevo, a través de preguntas, de motivar al estudiante al repaso de contenidos ya estudiados. En el libro de noveno, se profundiza en el estudio y clasificación de la oración transitiva; progresivamente, se presentan las oraciones transitivas oblicuas y reflejas. Es importante recalcar que se visualiza, en las estructuras arbóreas, la diferencia entre oraciones transitivas oblicuas y oraciones transitivas reflejas; asimismo, se enfatiza el hecho de que, en esta última, el sujeto puede ser correferencial tanto con el CD como con el CI. En cuanto a su valor transitivo y reflejo, el tema se resume cuidadosamente al final.

Respecto de las oraciones recíprocas, a través de las estructuras arbóreas se evidencia claramente la reciprocidad verbal; obsérvese la Figura $\mathrm{N}^{\circ} 16$ ( $9^{\circ}$, pág. 147).

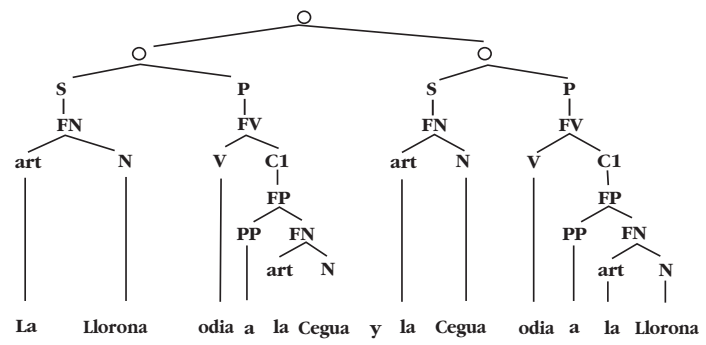

- Observe que, en cada caso, la FN del C1 es similar al sujeto de la otra oración; por tanto, indican que la acción verbal se ejerce recíprocamente entre los sujetos.

Fig. № 16

Finalmente, en cuanto a la oración intransitiva, se enfatiza el hecho de que su único requisito es no presentar el complemento directo, aunque sí puede presentar uno o varios complementos circunstanciales.

Así pues, en los libros de la serie Hacia el siglo XXI, en el desarrollo del tema de los tipos de complementos y de oraciones, los contenidos no se presentan mecánicamente, sino de manera dialógica; se parte de los conocimientos previos del alumno, se procura adelantarse a sus inquietudes y reflejarlas en las participaciones de los personajes. Se le guía por medio de preguntas a analizar las oraciones; luego, por medio de preguntas, se le presentan las respuestas apropiadas en los ejercicios y actividades. Se le ofrecen constantes prácticas de reconocimiento y análisis. En fin, se impulsa la construcción o la búsqueda de diversos tipos de oraciones en periódicos, revistas o canciones; se promueve la participación activa, el trabajo en parejas o en grupo (para construcción de ejemplos o revisión de éstos) y la investigación. Asimismo, se lo insta a componer canciones, poemas, etc.; también, se le plantean juegos de competencia donde aporte ejemplos de distintos tipos de oraciones, de su contexto diario. Nuevamente, cabe recalcar que con lo anterior se logra apreciar la lengua viva, se propone un uso más espontáneo del lenguaje y se enfatiza el carácter lúdico como un medio de aprender de manera más ágil y espontánea.

Las categorías gramaticales se abordan en capítulos separados; destacaremos algunos aspectos relevantes. En cuanto a las preposiciones, el tema se estudia con diferente grado de complejidad según el nivel. Se refuerza su valor de nexo; a propósito, véase la Figura 17 ( $8^{\circ}$, pág. 124).

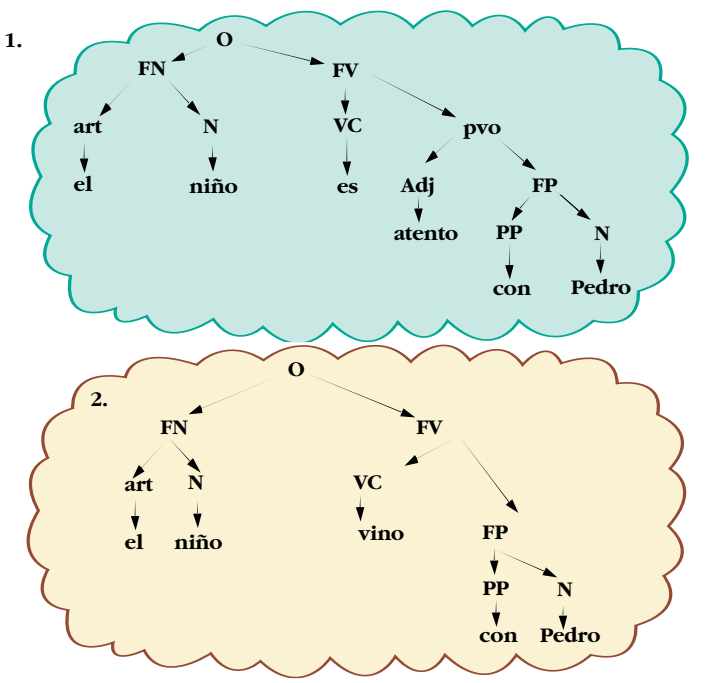

Fig. $\mathrm{N}^{\circ} 17$ 
"En consecuencia, en la primera estructura arbórea, "con Pedro" se relaciona con el predicativo, cuyo núcleo es el adjetivo "atento", y, en el segundo árbol, la relación de "con Pedro" es con la frase verbal, cuyo núcleo es el verbo "vino".

En lugar de la palabra "Pedro", se pueden poner las palabras "María, Juana y Laura". "El niño es atento con María, Juana y Laura", "El niño vino con María, Juana y Laura", sin que la palabra con sufra ningún cambio de género ni de número ni de tiempo. Por eso, esa palabra es invariable."

En el libro de octavo, se destaca el significado de las preposiciones y también las contracciones "al" y "del". Se enuncia el valor y uso de las preposiciones como un asunto de inseguridad lingüística y de empleo prestigioso (8º pág. 127):

"El uso de las preposiciones crea problemas de inseguridad lingüística (¿Cómo se dice: camisa a rayas o camisa de rayas?) y de variaciones respecto del habla culta o de la lengua literaria. [...] se va a distinguir entre uso no prestigioso de la preposición frente a uso prestigioso o de más prestigio".

En el libro de noveno, por su parte, se presentan y dirimen, a través de los personajes, situaciones que han creado inseguridad lingüística, tales como "vaso de agua" y "Se solicita guarda nocturno con o sin experiencia” (9, págs. 175, 176).

En lo relativo a las conjunciones, se presenta un ejemplo muy claro de diferentes conjunciones y cómo varía el significado; luego, se le solicita al estudiante analizar el valor de dichos nexos, según puede apreciarse en la Figura $\mathrm{N}^{\circ} 18$ ( $8^{\circ}$, pág. 129).

\section{Ahora observe:}

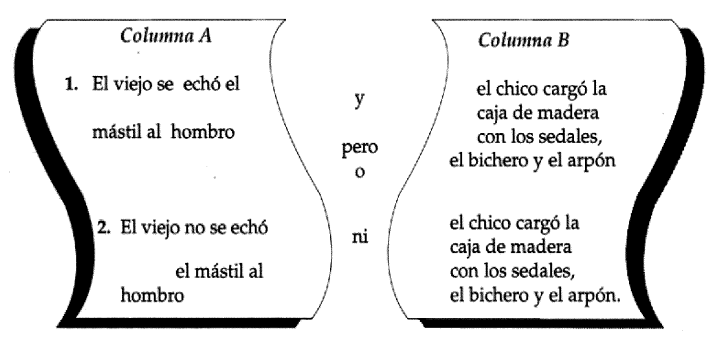

¿Podrá manifestarse cada una de esas oraciones en forma aislada como un enunciado? ¿Qué función desempeñan las palabras y, pero, o y ni?

Fig. $\mathrm{N}^{\circ} 18$
Por otra parte, se enfatiza visualmente, como recurso nemotécnico, su valor de "puente" entre elementos correlativos, lo cual puede verse en la Figura 19 (9, pág. 234):

¡Bien! Ambos tienen razón. Podemos comparar la conjunción con un puente que une dos casas:

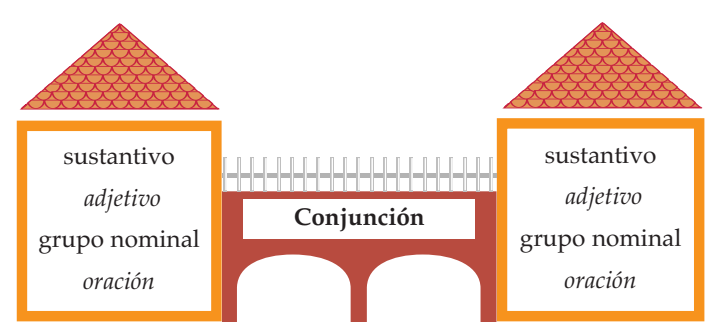

Fig. $\mathrm{N}^{\circ} 19$

En las prácticas respectivas, se presentan fragmentos de cánticos nacionales, adivinanzas, ejercicios para completar espacios, conjunciones para redactar ejemplos y, también, se les pide escuchar a compañeros y profesores para determinar, en el uso oral cotidiano del lenguaje, las conjunciones más frecuentes.

En lo tocante a los pronombres, hay varios aportes sumamente importantes. Primeramente, los títulos resultan sugestivos: "No se vale repetir", "A sustituir el nombre!" ( $8^{\circ}$, pág. 164; $9^{\circ}$, pág. 128) y ubican al estudiante en el punto central de la definición.

En octavo año, el tema se introduce por medio de una transcripción oral de un texto del español de Guanacaste. Posteriormente, se presentan dos cuadros comparativos entre los pronombres según el modelo académico y según el modelo costarricense ( $8^{\circ}$, págs. 166167); en este último, se incorporan las formas usted, ustedes, vos y sus correspondientes formas átonas. Seguidamente, se explica el uso pronominal general hispanoamericano $\left(8^{\circ}\right.$, pág. 168):

"En Hispanoamérica es general el uso de ustedes, segunda persona plural, en todas las situaciones comunicativas e independientemente de aspectos geográficos, de grupo social, de estilo -formal, no formal-, de tema, etc. Este rasgo unificador no es compartido por la segunda persona singular, que se ve condicionada por las características del interlocutor-sociales, generacionales, etc.-, del 
tema y del contexto situacional. Así las cosas, el uso de los pronombres de segunda persona singular refleja algunos aspectos de la organización sociocultural de los pueblos.

En Costa Rica, tal como vimos, conviven tres formas pronominales de segunda persona -usted, vos y tú-."

Luego, se sugiere organizar un debate en torno a las distintas situaciones comunicativas para el empleo de los pronombres de segunda persona singular. Y, seguidamente, se ofrecen los datos relevantes de las situaciones de uso de dichas formas pronominales.

En lo que respecta a las interjecciones, el título y el inicio del tema resultan muy apropiados; las preguntas ubican al alumno en el uso cotidiano del lenguaje y en reflexionar la función de las interjecciones; véase la Figura № 20 (9º, pág. 66). Los ejercicios se centran en compartir con los compañeros de clase así como con las amistades acerca de cuáles interjecciones utilizan con mayor frecuencia y en qué situaciones. También, se les pide trazar un dibujo para alguna interjección.

ENTRE EMOCIONES Y ÓRDENES

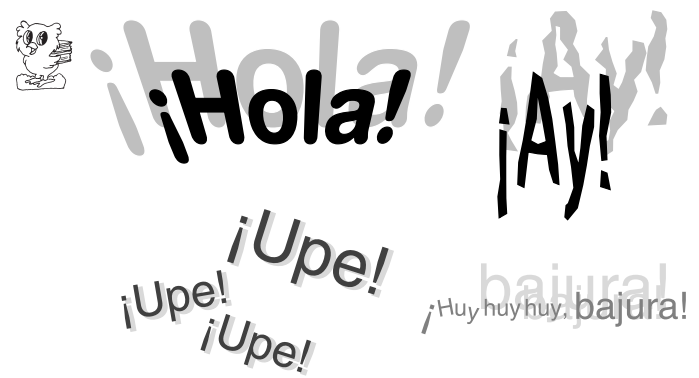

Fig. $N^{\circ} 20$

\section{Tratamiento de los contenidos léxicos}

Interesa aquí el desarrollo de un vocabulario variado, con posibilidades de usos apropiados y que manifiesten significativamente lo que se quiere expresar.

En este particular, se presentan y explican dos tipos de vocabulario: el activo y el pasivo. Se recalca el hecho de que, al es- tudiar el idioma español, es importante adquirir un vocabulario creciente porque ello le permitirá al hablante comprender y manejar mejor la información de los textos literarios, de los medios de comunicación masiva, de las diferentes disciplinas de estudio, etc. También, se hace hincapié en que, al ampliar el vocabulario, se logra un mayor acceso a la variante de prestigio, en lo oral y lo escrito.

Se integra el léxico en el discurso, al remitir al estudiante al trabajo con textos presentes en otros capítulos del libro en uso. Se busca apreciar el léxico, no como algo aislado, sino como una parte integrante de los otros componentes lingüísticos (pragmático, conceptual, discursivo, etc.).

Debido a la importancia de impulsar el enriquecimiento progresivo del léxico desde el comienzo, para ampliar el vocabulario de los estudiantes, se propicia el contacto con palabras nuevas y se le dan lineamientos para el uso del idioma.

Se ofrecen actividades de carácter lúdico (competencia, sopas de letras, bombas, refranes, trabajo con lecto-escritura) con el fin de incentivar el trabajo grupal, la práctica espontánea, la honestidad, la competencia sana. Tales actividades constituyen un recurso nemotécnico importante; además, permiten motivar a los jóvenes, desarrollar una actitud positiva hacia el léxico, la expresión oral y la escrita.

Por ejemplo, en el texto de octavo año (pág. 208), se establece la importancia del estudio del componente léxico, sea para comunicarse con eficiencia y economía, sea para comunicarse con redundancia, pero no se hace referencia a la "corrección":

"Ahora bien, en lo que toca a la cantidad de vocabulario y su importancia, podría decirse que, como bien sabemos, las palabras son portadoras de significados o conceptos. En este sentido, quien tiene más vocablos posee un universo conceptual más extenso. Y, como consecuencia, puede comprender mejor el mundo que lo rodea e incluso modificarlo. Una mayor riqueza léxica da la posibilidad de comunicarse con eficiencia y economía o con redundancia, cuando la situación comunicativa así lo requiera."

También, se dedica un apartado especial al estudio del lenguaje de los adolescentes, cuyo propósito es reflexionar acerca de 
las peculiaridades de este lenguaje y de las motivaciones para "reinventar" el léxico; así como los adolescentes costarricenses manifiestan una actitud creadora en el lenguaje, este fenómeno es general a cualquier país.

Otro ejemplo puede tomarse del libro de texto de noveno año, cuyo título en sí mismo ya suscita una discusión: "Para desternillarse de risa!", en oposición a la frase popular "destornillarse de risa".

En conclusión, podemos afirmar que, para lograr los cometidos, el clima del aula debe privilegiar un diálogo abierto y honesto entre los profesores y los estudiantes. Por consiguiente, se deben fomentar la creación, la actitud crítica, en acciones de expresión formal e informal, introduciendo temas generales e interdisciplinarios, que incluyan intereses escolares y comunales, en un marco constructivista.

"Siguiendo a Papert, es en la actividad de creación donde ocurre la movilización de la persona en su totalidad, de su sentido estético, su conciencia ética, su raciocinio lógico-matemático, su estructura emocional, etc. Papert nos habla de la necesidad de que herramientas para ayudar a aprender, objetos 'para pensar con' estén a la disposición del sujeto en los ambientes de aprendizaje" (Moraschin y Nevado, 1994, citado por Magaly Zúñiga)".

Seymour Papert, creador del construccionismo, teoría de la educación, fundamentada en el desarrollo cognitivo de J. Piaget, señala que uno de los principios fundamentales radica en que la construcción que tiene lugar en la "cabeza" de las personas frecuentemente ocurre de manera especialmente provechosa cuando tiene un soporte en una construcción de tipo más público, es decir, que puede ser mostrada, discutida, examinada, probada, admirada; como, por ejemplo, un castillo de arena, una casa de Lego, un programa de computadora, un poema (Papert, 1993: 142). A diferencia de Piaget, quien se interesaba más por los procesos internos que se generan en el niño, Papert privilegia investigar la influencia de los elementos culturales útiles para la construcción del pensamiento.

En fin, la meta la constituye la formación de alumnas y alumnos comprometidos, partici- pantes, colaboradores entusiastas; todo dentro de un enfoque constructivista. El constructivismo parte de la idea de que el conocimiento es una construcción humana, lo cual implica que el sujeto desempeña el papel protagónico en la construcción del conocimiento. Lo anterior no significa, de ninguna manera, una actitud entrópica, anárquica en clase, sino, por el contrario, un profesor o profesora que sea capaz de guiar a sus estudiantes, que les lleve la delantera en la propuesta de problemas que impliquen siempre un desafío -en menor o mayor grado-; debemos, por tanto, destacar que:

"es muy importante que los maestros ofrezcan a los niños materiales, situaciones y ocasiones que les permitan avanzar. No se trata simplemente de permitir a los niños hacer cualquier cosa. Se trata de presentarles situaciones que ofrezcan nuevos problemas, problemas que emanen uno del otro. Necesitamos una mezcla de dirección y libertad" (Piaget, en Evans. 1982:75).

\section{Referencias bibliográficas}

Abarca, Sonia. Psicología de la educación. San José, Costa Rica: CIPED-MEP. 1993.

Alcalá, Antonio. El concepto de corrección y prestigio lingüísticos. México: Editorial trillas, 2 edición, 1986.

Ander-egg, Ezequiel y María José Aguilar. Cómo aprender a hablar en público. San José, Costa Rica: EUNED, 2 edic. 1999.

Antunes, Celso. Manual de técnicas de dinámicas de grupos de sensibilización y lúdico-pedagógicos. Buenos Aires: Editorial Lumen. 1992.

Bernardini, Amalia y José Alberto Soto. La educación actual en sus fuentes filosóficas. San José. 1987.

Bolaño, Sara. Introducción a la teoría y práctica de la sociolingüistica. México: Editorial trillas, 1982. 
Bolaños, Carolina et al. "Síntesis de algunos conceptos teóricos del constructivismo". En: Estudio psicogenético de algunos contenidos del programa de Química: reflexiones y sugerencias acerca de su enseñanza. Seminario de graduación para optar por el grado de Licenciatura en la Enseñanza de la Química. Facultad de Educación, Universidad de Costa Rica. 1992.

Gómez, Margarita et al. El niño y sus primeros años en la escuela. México: Editorial Biblioteca para la actualización del maestro. 1995.

Guba, Egon. Constructivismo. El paradigma, el aprendizaje, la enseñanza y el cambio conceptual. Colombia: Editorial Publi Adco. 1994.

López Morales, Humberto. Sociolingüistica. Madrid: Editorial Gredos. 1989.

Los juegos tradicionales y sus proyecciones pedagógicas. http//www.raracu. com/apuntes/educacion/juegos_peda/

Maat, Hendrien. Elementos del enfoque socioconstructivista en los aprendizajes. San José, Costa Rica: SIMED, Ministerio de Educación Pública, Centro Nacional de Didáctica. 1993.

Müller, Marta Virginia. Técnicas de comunicación oral. San José, Costa Rica: Editorial UCR. 1993.

Pérez, Rafael Ángel et al. Estrategia general para la construcción del conocimiento en una perspectiva constructivista. San José, Costa Rica: SIMED, Ministerio de Educación Pública. S.f.

Rodino, Ana María y Ronald Ross. Problemas de expresión en el estudiante universita- rio costarricense: un estudio de lingüistica aplicada. San José, Costa Rica: EUNED, 1985.

Rojas Porras, Marta. "El registro escrito. Un enfoque para su enseñanza”. En: Revista Educación, Universidad de Costa Rica. Vol. 15, No 1: PP 49-54, 1991.

Romero, Hernando. Pedagogía constructivista de la transformación, proyecto educativo institucional. Colombia: Fundación CEIMPE. 1995.

Sánchez Corrales, Víctor Manuel et al. Español 8. San José, Costa Rica: Editorial de la UCR, PROMECE-Ministerio de Educación Pública. Serie Hacia el Siglo XXI. 1996.

Trautmann, Thomas. "Alte Spiele (wieder) entdechen -eine Hoffnung für die Pädagogik?” En: Erich Renner (Hrsg.)) Spiele der Kinder. Beltz, Weinheim. Citado en: http.//www.raracu.com/ apuntes/educacion/juegos_peda.

Víquez Jiménez, Alí et al. Español 9. San José, Costa Rica: Editorial de la UCR, PROMECE-Ministerio de Educación Pública. Serie Hacia el Siglo XXI. 1996.

Walter, Günter. Spiel und Spielpraxis in der Grundscbule. Ludwig Auer GmbH, Donauwörth. 1993. Citado en: http.//www.raracu.com/apuntes/educacion/juegos_peda.

Zúñiga Céspedes, Magaly. "Del constructivismo al construccionismo". Documento elaborado para la Fundación Omar Dengo. 1997. 